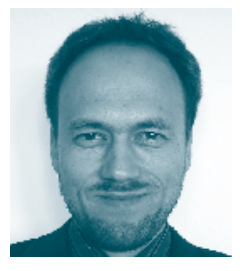

Petter Viksveen, registrert homeopat MNHL, BA, MSC

\title{
Alternativ på frammarsj
}

\author{
Komplementær og alternativ medisin får stadig større innpass hos pasienter, \\ behandlere og ved de medisinske og helsefaglige utdanningene.
}

$\mathbf{P}$ asienters interesse for og bruk av komplementær og alternativ medisin (KAM) har økt betydelig de siste tiårene (1-2). En undersøkelse publisert av Nasjonalt informasjonssenter av alternativ behandling viste at om lag halvparten av den norske befolkningen har brukt KAM i løpet av de siste tolv månedene (3), kvinner noe oftere enn menn. Homeopati er en av de hyppigst anvendte KAM-terapiformene i flere land i og utenfor Europa (1-2). Stadig flere sykepleiere og annet helsepersonell har vist interesse for og tatt utdanning i KAM. Økt interesse for og bruk av KAM fører også til økt behov for at medisinsk personell kjenner til disse behandlingsformene, for best mulig å kunne møte pasienter som har erfaringer med og spørsmål om slik behandling (4).

\section{Medisinsk utdanning}

Det har blitt vanlig å undervise i KAM ved medisinske utdanninger i Europa (5). Blant leger i Storbritannia er homeopati det mest populære etterutdanningstilbudet, både når man tar konvensjonell og KAM-etterutdanning i betraktning. I USA tilbys KAM-kurs ved de fleste medisinutdanningene, gjerne som en obligatorisk del av studiet i løpet av de første to årene. Allerede på 90-tallet var KAM godt på vei inn i utdanningen for amerikanske leger $(6,7)$.

Kvinnelige medisinstudenter vurderer oftere KAM som positivt, og kvinner mener i større grad at disse behandlingsformene spiller en viktig rolle i helsetilbudet enn menn (8). Kvinner vil også oftere enn menn lære mer om både KAM-teori og -praksis, og ønsker å bruke en større del av studietiden på dette enn mennene. En konsekvens av dette er at kvinnelige medisinstudenter i større grad enn sine mannlige medstudenter kan ha positiv innflytelse på utviklingen av integrert medisin.

\section{Sykepleie og sykepleierutdanning}

Flere forskere har påpekt at sykepleiere bør ha kunnskaper om KAM-terapier, slik at de blir bedre i stand til å møte pasienter, gi dem råd og være bevisst etiske så vel som faglige spørsmål $(9,10)$.
Sykepleierutdanninger vurderer i økende grad å inkludere KAMterapier som en del av studiet, sannsynligvis motivert av økende etterspørsel blant pasientene. En undersøkelse blant 585 amerikanske sykepleierutdanninger viste at de fleste inkluderer KAM i sitt undervisningsprogram (11). Dette er i tråd med en egen resolusjon om KAM som ble publisert av Det hvite hus i 2002 (12).

En studie blant 627 ansatte og studenter ved universitetet i Minnesota viste at over 90 prosent mener klinisk pleie bør integrere det beste fra både konvensjonell og KAM-behandling, og at helsepersonell bør være i stand til å gi råd til pasienter om bruk av KAM-metoder (13). Den største interessen for KAM fant man ved fakultetet som organiserer sykepleierstudiet. I en undersøkelse hvor 90 prosent av alle britiske universiteter deltok fant man 108 kurs eller moduler i KAM og ytterligere 47 institusjoner planla fremtidige kurs (14). KAM var langt hyppigere en del av sykepleierstudiet enn medisinstudiet.

Nesten halvparten av alle de amerikanske statlige sykepleierstyrene har en politikk som tillater sykepleiere å praktisere KAMterapi, 13 prosent er i ferd med å vurdere dette, og ingen av de resterende styrene fraråder sykepleiere slik praksis (15). Registrerte sykepleiere inkorporerer i økende grad KAM-terapier i praksisen $\sin (9)$.

\section{Tenker helhetlig}

Sykepleiere er i utgangspunktet opptatt av helhetlig tankegang $(10,16)$, noe som også er karakteristisk for en rekke KAM-terapier, for eksempel homeopati (16). En holistisk tankegang hjelper sykepleiere med å være til stede for pasientene - fysisk, psykisk og åndelig (10). Sykepleiere har dessuten en utmerket posisjon med hensyn til å bidra til integrasjon av KAM-terapiformene. De har et solid fundament i en vestlig biomedisinsk helsemodell og dermed et godt grunnlag for å bedre vitenskapelig basis for bruk av KAM. KAM-terapier kan tas inn i en sykepleiefaglig kontekst på en relativt enkel måte (9). KAM som del av studiet viser seg å 
bidra til at medisinstudenter takler stress bedre og $ø$ ker evnen til empati (17). Dette er elementer som faller helt naturlig inn i sykepleierstudiet. Profesjonell sykepleie kan bidra til økt kvalitet av KAM gjennom evaluering, refleksjon og et holistisk tankesett i vurderingen og utøvelsen av slike terapiformer (9).

\section{Erfaringer med KAM-utdanning}

En rekke tilnærminger har vært forsøkt for å øke helsepersonells kompetanse i KAM $(18,19)$. Fra undervisning av et svært begrenset antall timer i grunnutdanningen av leger og sykepleiere, til mer eller mindre fullstendige utdanningsopplegg. I en evaluering av etterutdanningen i homeopati for leger i Storbritannia fant en at kursdeltakerne ikke bare lærte det rent homeopatfaglige, men også at dette bidro til å bedre deres praksis som leger (18). Legene sa at de blant annet:

, Ble flinkere til å lytte, mindre avvisende overfor pasienter \ Fikk et videre syn på medisinsk behandling generelt

, Fikk et nytt syn på kronisk sykdom

, Ble mindre opptatt av cellulær biokjemi

ı Ble mer bevisst på å se pasientene som individer og hele mennesker

, Fikk økt interesse for klinisk medisin, og klinisk praksis ble «rikere» og mer fascinerende

, Ble mer bevisst pasientens selvhelbredende evner

, Ønsket i økende grad å henvise pasienter til andre behandlere

I en undersøkelse av kanadiske universiteter som tilbyr medisinutdanning, svarte deltakerne at mer utfyllende KAM-utdanning bør søkes utenfor de fastsatte medisinstudiene (20). I Norge eksisterer ett studium i homeopati som er skreddersydd for sykepleiere og andre med helsefaglig bakgrunn, ved Skandinavisk Institutt for Klassisk Homeopati. Studiet strekker seg over tre og et halvt år

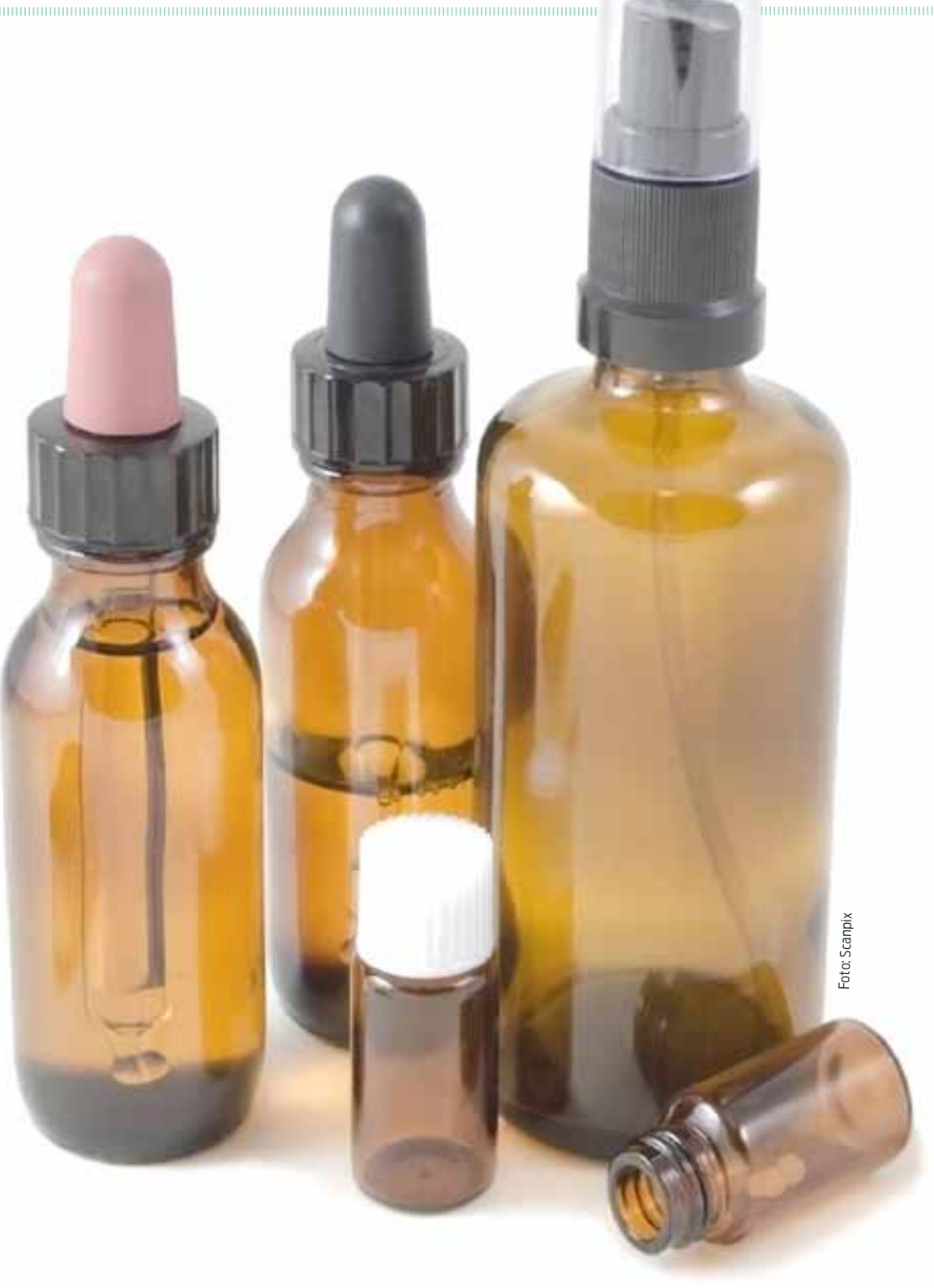

på deltid, og krever at søker har sykepleiefaglig medisinsk grunnkompetanse eller minimum grunnfag i medisin (60 studiepoeng). Utdanningen gir kompetanse til å praktisere homeopati og til å bli medlem av forbundet som organiserer homeopater (16). Forbundet er tatt opp i Register for alternative behandlere. Sykepleiere kan også ta en modul av studiet og får da kompetanse til å veilede pasienter i bruk av KAM-behandling.

\section{Utdanning av fakultetenes ansatte}

Ettersom interessen for og bruk av KAM-terapier øker, og i stadig større grad blir en integrert del av helsefaglige utdanninger, føl-

\section{Blant leger i Storbritannia er homeopati det mest populcere etterutdanningstilbudet.}

ger behovet for høyere KAM-kompetanse blant de ansatte. Ulike tilnærminger til dette eksisterer.

The University of Washington School of Nursing og Bastyr University har sammen utviklet et fire ukers intensivt KAM-kurs. Hensikten er å øke kunnskap om KAM blant fakultetets ansatte (19). Det ble fokusert på bredden av KAM-terapier, den teoretiske og kulturelle kontekst som disse terapiene er rotfestet i og det potensielle bidraget som disse behandlingsformene kan ha på ulike populasjoner. Et mer intensivt undervisningsprogram som dette, ga positive læringseffekter på samtlige målte parametere. 
Et tidsmessig begrenset opplegg eksisterer ved Skandinavisk Institutt for Klassisk Homeopati. Her kan sykepleiere ta grunnkurs i homeopati, som er en egen modul av studiet og som gir en solid innføring i faget.

\section{Det offentlige helsetilbudet}

I henhold til Verdens helseorganisasjon er KAM en integrert del av det offentlige helsetilbudet i flere land i verden, også i Europa. Homeopati har eksistert som en del av det offentlige helsetilbudet i Storbritannia i mange år, hvor det også finnes fem homeopatiske

\section{Sykepleiere er i utgangspunktet opptatt av helhetlig tankegang.}

sykehus (16). Et annet eksempel er Brasil, hvor myndighetene i 2006 besluttet å integrere homeopati og tre andre KAM-terapier i det offentlige helsetilbudet, med 150 millioner innbyggere som målgruppe. Dette ble besluttet blant annet på grunnlag av Verdens helseorganisasjons anbefalinger.

\section{Helsefremmende behandling}

Pasienter har erfaringer med og ønsker økt informasjon om KAM. Frem til for noen tiår siden var det få helsefaglige utdanninger som inkluderte KAM som en del av studiet. Situasjonen har endret seg betraktelig, blant annet med en solid økning i tilbud om KAMundervisning i medisin- og sykepleierfaglig utdanning. Sykehus i andre land har begynt å tilby KAM som en del av et integrert helsefaglig tilbud (16). En slik tilnærming har fokus på helsefremmende behandling. Norge er et foregangsland når det gjelder utvikling av KAM-lovverk og forskning på kroppens selvhelbredende evner. Skrautvol (16) har påpekt at KAM bør inngå som en del av behandlingen av kronisk syke ved sykehusenes poliklinikker, og at sykepleiere, fysioterapeuter og leger med homeopatiutdanning bør få lisens og muligheter til å praktisere innenfor helsevesenet.

\section{Integrert helsetilbud}

Amerikanske myndigheter bidrar med økonomisk støtte for at
KAM skal være en del av utdanningsprogrammet for helsepersonell. Norske sykepleierstudier har allerede delvis introdusert en innføring av KAM i undervisningen. Lærere i helsefaglige utdanninger behøver økt kunnskap om KAM. Gjennom utdanning i

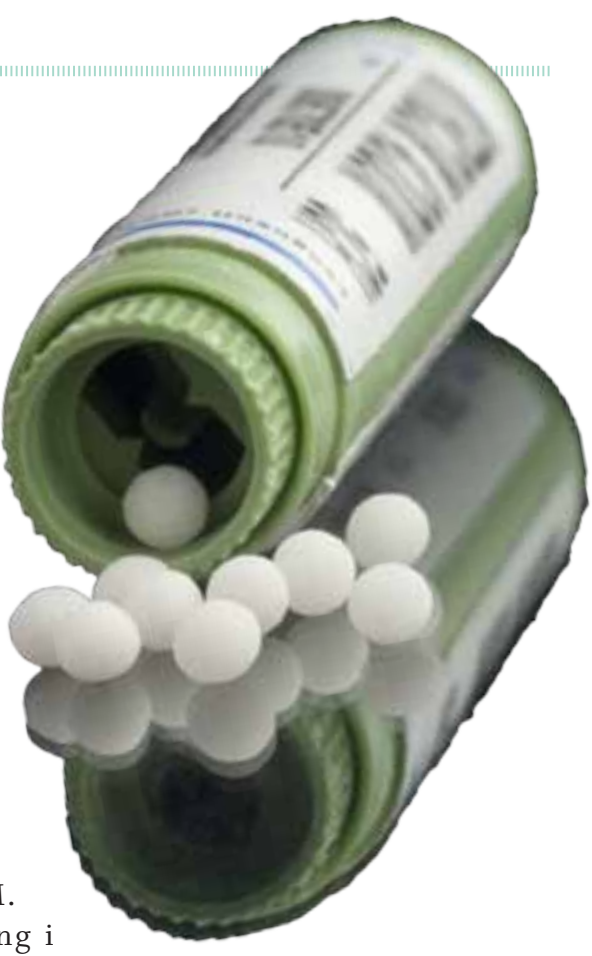

KAM kan helsepersonell få

$ø$ kt innsikt $\mathrm{i}$ andre tankesett og kunnskap om hvordan pasienter på nye måter kan bidra til egenomsorg. Det kan også føre til at helsepersonells kunnskap om sikkerhet og begrensninger ved både konvensjonell og KAM-behandling øker, samt at disse to tilnærmingene ikke utelukker hverandre, men kan benyttes som deler av et integrert helsetilbud.

\section{Sykepleiere brobyggere}

Introduksjon av KAM som del av helsefaglig utdanning bidrar til medisinsk pluralisme (21). Den biomedisinske «kultur» må ikke bare tilpasse seg personer fra ulike nasjoner med ulike kulturelle bakgrunner, men også ulike terapeutiske kulturer. Konvensjonell og KAM-behandling kan og bør integreres på en mer effektiv måte, til fordel for pasientene. Terapeuter som utøver KAM-behandling kan i økende grad arbeide side om side med ulike former for konvensjonell behandling i et miljø der gjensidig respekt og forståelse regjerer. Dette er også i tråd med Europarådets og Verdens helseorganisasjons resolusjoner om KAM. Sykepleiere er spesielt godt egnet til brobygging mellom konvensjonell og KAM behandling, både når det gjelder forskning, fagutvikling og i sykehusenes poliklinikker (16). IIII
LITTERATUR

NOU 1998: Alternativ medisin. Norges Offentlige Utredninger. Utredning fra et utvalg oppnevnt av Sosial- og helsedepartementet april 1997. Avgitt til Sosial- og helsedepartementet 15. desember 1998.

2. Tindle HA, Davis RB, Phillips RS, Eisenberg DM. Trends in use of complementary and alternative medicine by US adults: 1997-2002. Alternative Therapies in Health and Medicine 2005 $11(1): 42-49$

3. Nasjonalt informasjonssenter innen alternativ behandling (NIFAB). Bruk avaltentist lastet ned fra htp://www.rifab.no/ om_alternati_behandling/atternativ_behandling_i_norge/bruk_av_ab_i norge 08.04.2010

4. Kaczorowski J, Patterson C, Arthur H, Smith K, Mills DA. Complementary therapy involvement of physicians: implications for practice and learning. Complementary Therapies in Medicine 2002; 10: 134-140.
5. Ernst E. Medical students' attitudes towards complementary medicine: systematic review. Student BMJ 1998; 6: 204-6.

6. Carlston M, Stuart MR, Jonas W. Alternative medicine instruction in medical native medicine instruction in medical schools and family practice residency programs. Family Medicine 1997; 29(8):

7. Brokaw JJ, Tunnicliff G, Raess BU, Saxon DW. The teaching of complementary and alternative medicine in U.S. medical schools: A survey of cours directors. Academic Medicine 2002: 77(9): 876-881.

8. Greenfield SM, Brown R, Dawlatly SL, Reynolds JA, Roberts S, Dawlatly RJ. Gender differences among medical students in attitudes to learning about complementary and alternative medicine. Complementary Therapies in Medicine 2006; 14: 207-212.

9. Frisch N. Standards for holistic nursing practice: A way to think about our care that includes complementary and alternative modalities». Online
Journal of Issues in Nursing 2001; 6(2): 4. Sist lastet ned fra http://www. nursingworld.org/MainMenuCategories/ANAMarketplace/ANAPeriodicals/ OJIN/TableofContents/Volume62001/ No2May01/HolisticNursingPractice. aspx 08.04.2010

10. Trossman S. Holistic nursing: The goal is the whole person. Nursing World, The American Nurses Association, 1998 Sist lastet ned fra

http://www.nursingworld.org/MainMenuCategories/ANAMarketplace/ANAPeriodicals/TAN/1998/HolisticNursing aspx 08.04.2010

11. Fenton MV, Morris DL. The integration of holistic nursing practices and complementary and alernative modalities into curricula of schools of nursing. Alternative Therapies in Health and Medicine 2003; 9(4): 62-67.

12. White House Commission on Complementary and Alternative Medicine Po licy. Chapter4: Education and training of health care practitioners. March, 51-68, 2002
13. Kreitzer MJ, Mitten D, Harris I, Shandeling J. Attitudes toward CAM among medical, nursing, and pharmacy faculty and students: a comparative analysis. Alternative Therapies in Health and Medicine 2002; 8(6): 44-53.

14. Morgan D, Glanville H, Mars S, Nathanson V. Education and training in complementary and alternative medicine: a postal survey of UK universities, medical schools and faculties of nurse education. Complementary Therapies in Medicine 1998; 6: 64-70.

15. Sparber A. State boards of nursing and scope of practice of registered nurses performing complementary therapies. Online Journal of Issues in Nursing 2000 6(3). Sist lastet ned fra http://www. nursingworld.org/MainMenuCategories/ANAMarketplace/ANAPeriodicals/ ries/ANAMarketplace/ANAPeriodicals/ OJIN/TableofContents/Volume62001/
No3Sept01/ArticlePreviousTopic/ No3Sept01/ArticlePreviousTopic/ 08.04.2010

16. Skrautvol K. Komplementærmedisin bør inn i behandlingen av kronisk syke ved sykehusenes poliklinikker. Tidsskriftet Sykepleien 2007; 13: 32-34.

17. Flannery MA, Love MM, Pearce KA, Luan JJ. Communication about complementary and alternative medicine: perspectives. Alternative Therapies in Health and Medicine 2006; 12(1): in Health

18. Reilly DT. Homeopathy: Increasing scientific validation. Alternative Therapies in Health and Medicine 2005: 11(2): 29-31.

19. Cornman BJ, Carr CA, Heitkemper MM Integrating CAM into nursing curricula: CAM camp as an educational intervention. Explore 2006; 2(3): 226-231.

20. Ruedy J, Kaufman DM, MacLeod H. Alternative and complementary medicine in Canadian medical schools: A survey. Canadian Medical Association 1999; 160(6): 816-817.

21. Kaptchuk TJ, Eisenberg DM. Varieties of healing. 1: Medical pluralism in the United States. Annals of Internal Medicine 2001; 135: 189-195. 